\title{
Detection and comparison of microRNA expression in the serum of Doberman Pinschers with dilated cardiomyopathy and healthy controls
}

\author{
Carola Steudemann ${ }^{1}$, Stefan Bauersachs ${ }^{2}$, Karin Weber ${ }^{1}$ and Gerhard Wess ${ }^{1 *}$
}

\begin{abstract}
Background: Dilated cardiomyopathy (DCM) is the most common heart disease in Doberman Pinschers. MicroRNAs (miRNAs) are short non-coding RNAs playing important roles in gene regulation. Different miRNA expression patterns have been described for DCM in humans and might represent potential diagnostic markers. There are no studies investigating miRNA expression profiles in canine DCM. The aims of this study were to screen the miRNA expression profile of canine serum using miRNA microarray and to compare expression patterns of a group of Doberman Pinschers with DCM and healthy controls.
\end{abstract}

Results: Eight Doberman Pinschers were examined by echocardiography and 24-hour-ECG and classified as healthy $(n=4)$ or suffering from DCM $(n=4)$. Total RNA was extracted from serum and hybridized on a custom-designed 8x60k miRNA microarray (Agilent) containing probes for 1368 individual miRNAs. Although total RNA concentrations were very low in serum samples, 404 different miRNAs were detectable with sufficient signal intensity on miRNA microarray. 22 miRNAs were differentially expressed in the two groups $(p<0.05$ and fold change $(F C)>1.5)$, but did not reach statistical significance after multiple testing correction (false discovery rate adjusted $p>0.05$ ). Five miRNAs were selected for further analysis using quantitative Real-Time RT-PCR (qPCR) assays. No significant differences were found using specific miRNA qPCR assays ( $p>0.05$ ).

Conclusions: Numerous miRNAs can be detected in canine serum. Between healthy and DCM dogs, miRNA expression changes could be detected, but the results did not reach statistical significance most probably due to the small group size. miRNAs are potential new circulating biomarkers in veterinary medicine and should be investigated in larger patient groups and additional canine diseases.

Keywords: Dobermann Pinscher, Dilated cardiomyopathy, miRNA, Serum, Dog, Microarray

\section{Background}

Dilated cardiomyopathy (DCM) is the most common acquired heart disease in large- and giant-breed dogs. DCM in dogs is therefore an important cause of cardiac morbidity and death [1-3]. Doberman Pinschers are among the most frequently affected breeds. DCM in Doberman Pinschers is inherited and typically shows a unique disease progression with a late onset [1,4-8]. Most dogs with clinical signs of heart disease were diagnosed at an age of 5 to 10 years [9]. Doberman Pinschers at an age of 6 to 8 years showed a prevalence of $43.6 \%$

\footnotetext{
*Correspondence: gwess@lmu.de

${ }^{1}$ Clinic of Small Animal Medicine, LMU University of Munich, Veterinaerstrasse 13, Munich 80539, Germany

Full list of author information is available at the end of the article
}

and older dogs a prevalence of $44.1 \%$. Even if disease manifests itself with an increasing age, younger Doberman Pinschers are also affected. The cumulative prevalence of DCM in Doberman Pinschers in Europe was demonstrated to be $58.2 \%$ [8].

The natural progression of DCM can be characterized by three stages [1,6,9-11]. Stage I is defined by a morphologically and electrically normal heart. There is no evidence of clinical signs of heart disease in this phase. None of the currently available diagnostic tests can identify this stage. In the second stage (also called "occult stage"), morphologic and/or electrical derangement is presented in the absence of clinical signs of cardiac disease. Dogs typically appear absolutely normal to their owners, despite evidence of abnormalities detectable by

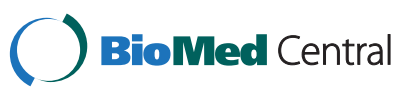


cardiac examination. Abnormalities consist of left ventricular enlargement and occurrence of ventricular premature contractions (VPCs). Morphological and electrical abnormalities may coexist or be of predominantly one form at the time of occult stage [1,12-15]. The diagnosis of stage II consists of echocardiographic evaluation of left ventricular dimensions and function and 24-hour ambulatory electrocardiogram (Holter monitoring) evaluating evidence of ventricular arrhythmias. The DCM in Doberman Pinschers usually starts with VPCs, which can lead to sudden cardiac death in about one third of the dogs. Later morphological changes typical for DCM develop, which can be detected by echocardiography. Stage III, the overt stage, is characterized by the presence of clinical signs of heart failure [1,12-15]. For prognostic and therapeutic but also for breeding purposes, it is essential to diagnose DCM before clinical signs develop.

Board-certified cardiologists recommend yearly screening of Doberman Pinschers for DCM by echocardiography and Holter examination, starting at two years of age $[4,8]$. The combination of echocardiography and Holter monitoring are considered to be the gold standard for the diagnosis of DCM in Doberman Pinschers. But both diagnostic methods have several disadvantages, including high financial costs for the owners, the need for specialized equipment and veterinary training, therefore limited availability and high interobserver variability [16]. The use of circulating biomarkers in the diagnostic approach would offer an attractive alternative because of widespread availability, quantitative nature, potential cost efficiency and minimally invasive sample collection [16]. Therefore various neurohormones and myocardial enzymes as biomarkers of DCM were evaluated [16-20].

MicroRNAs (miRNAs) are short (18 - 25 nucleotide in length) non-coding RNAs which play important roles in post-transcriptional gene regulation. miRNAs regulate gene expression by binding to the 3 '-untranslated region of their target mRNA and consequently attenuating protein translation. miRNAs are involved in multiple biological processes $[21,22]$. It is estimated that more than $60 \%$ of human genes are fine-tuned by miRNAs [23].

Multiple studies investigated the potential benefit of circulating miRNAs as noninvasive biomarkers and discovered a remarkable stability of miRNAs in blood [24-26]. The levels of miRNAs in serum are stable, reproducible, and consistent among individuals of the same species [26]. Endogenous circulating miRNAs are stably expressed in human serum, whereas synthetic miRNAs are immediately degraded [24]. However, the exact mechanism how miRNAs enter into the serum and how they are protected from enzymeatic degradation is still unknown [27].

A specific circulating miRNA expression pattern has been described for various pathological conditions. It is presumed that changes in the circulating miRNA expression pattern represent fingerprints for various diseases [28-30] and may even precede detectable changes of standard diagnostic tools [28,31]. Several studies in humans reported circulating miRNAs to be promising biomarkers for cancer $[24,30,32,33]$ and liver injury $[28,34]$.

Various studies evaluated differences of miRNA expression in heart diseases. Several miRNAs were found to be highly enriched in the heart [35-37]. miRNAs were shown to be involved in cardiac development, myocyte growth and arrhythmias following myocardial ischemia [38-43]. Experiments in mice have shown that gain or loss of function of individual miRNAs may elicit different forms of heart disease. Cardiac overexpression of miR-195 in transgenic mice initially induced pathological cardiac growth with disorganization of cardiomyocytes and progressed to an echocardiographically confirmed dilated phenotype at the age of six month that finally resulted in heart failure [44]. Inhibition of miRNA biogenesis revealed DCM, premature lethargy and heart failure in mice $[45,46]$. Liu et al. demonstrated the essential role of miR-133a in the cardiomyocyte proliferation: miR-133a-1 and miR-133a-2 double-mutant mice developed early large septal defects that led to perinatal death, whereas mice that survived to adulthood succumbed to DCM and heart failure. About $50 \%$ of surviving mice died from sudden death [47]. Findings of these studies support the assumption that specific miRNAs play an essential role in the control of cardiac growth and remodeling leading to a dilated phenotype of the heart. In 2007, Ikeda et al. detected different miRNA expression patterns in human heart samples from control patients and patients with DCM, aortic stenosis and ischemic cardiomyopathy (ICM). Eight miRNAs were differentially expressed in ICM and DCM which indicates that each form of heart disease is characterized by a specific miRNA expression profile. Among other miRNAs, let-7c, miR-21, miR-92 and miR-101 were deregulated in DCM diseased tissue in contrast to healthy controls [48]. Later experiments demonstrated miRNA expression differences in heart failure either caused by idiopathic or ischemic DCM and confirmed the aberrant expression of miR-92 in DCM [49]. Levels of miR-208, miR-208b and miR-499 were higher in human endomyocardial samples of DCM patients than in controls. Deregulation of individual miRNA expression was associated with a poor clinical outcome and therefore represents a potential prognostic marker of human DCM $[37,50]$. Satoh et al. found a significant difference in the expression of miR-21 in DCM diseased tissue as well [50]. An increased risk of DCM was also found in people with genetic polymorphisms in the pre-stages of miR-196a and miR-499 [51]. In humans with chronic heart failure caused by nonischemic DCM, miR-142-3p was found to be upregulated in peripheral blood cells [52]. 
However, circulating miRNAs are only emerging as potential diagnostic and prognostic biomarkers in cardiovascular disease. Cardiac hypertrophy, myocardial infarction and heart failure were associated with different expression profiles of circulating miRNA [25,31,53-58]. Several studies have also reported the potential of circulating miRNAs as diagnostic, prognostic and therapeutic marker for cardiovascular pathologies like coronary artery disease, stroke, diabetes mellitus or hypertension [55]. With the exception of one study in humans investigating miRNA expression in peripheral blood cells in chronic heart failure caused by different cardiomyopathies (including DCM [52]), studies about circulating miRNA expression patterns in human DCM do not exist to date.

Because of the increasing interest in canine genetics and the benefits of using the domestic dog as a model for human hereditary diseases, investigations on canine miRNAs were initiated [59-64]. In 2007, a search of genetic databases revealed significant conservation of miRNA genes between the domestic dog and the human. Expression levels of seven miRNAs were analyzed in several canine tissues. This was the first study that successfully used quantitative Real-Time RT-PCR (qPCR) assays originally designed for human miRNA detection and showed full conservation of mature sequences of canine and human miRNAs [61]. In 2008, Zhou et al. identified 357 miRNA candidates from the dog genome, 300 of which were orthologous to already characterized human miRNAs [60]. Deregulation of miRNA expression patterns has been reported in various canine neoplastic tissues and muscular dystrophy [59,62-64].

To our knowledge this is the first study about circulating miRNAs in canine DCM. The aim of this study was to investigate whether Doberman Pinschers with DCM and healthy controls display different serum miRNA expression patterns in order to evaluate a possible use of miRNAs as biomarkers in dogs.

\section{Results}

\section{Patient characteristics}

Eight Doberman Pinschers with a mean age of 8.6 years were included in the study and assigned to a DCM $(n=4)$ and a control group $(n=4)$. Analysis using the MannWhitney test revealed statistically significant differences between the two groups for the parameters 'ventricular premature contractions' (VPCs) and 'left ventricular enddiastolic volume' (LVEDV), 'left ventricular end-systolic volume' (LVESV, $\mathrm{p}=0.0143$ ) and 'ejection fraction' (EF, $\mathrm{p}=0.0286$; Table 1).

\section{Sample characteristics}

None of the dogs had evidence of renal disease with urea and creatinine values in reference ranges. Serum samples were stored at $-80^{\circ} \mathrm{C}$ for $240 \pm 144$ days (mean $\pm \mathrm{SD}$ ) prior to analysis. Circulating cardiac troponin I (cTnI) levels showed significant difference between the two groups. Total RNA amounts of the serum samples used did not differ between the two groups (for further baseline characteristics see Table 1).

\section{miRNA microarray}

By employing a highly sensitive and custom-designed 8x60k miRNA microarray (Agilent Technologies, Santa Clara, CA, USA), miRNA expression profiles of canine serum were determined. After subtracting background signals, a total of 404 individual miRNAs could be detected.

One sample of the DCM group was removed from further miRNA microarray analysis because of inconsistency of expression levels compared to other samples (Figures 1 and 2).

Expression of 22 miRNAs was different between the two groups $(\mathrm{p}<0.05$ and fold change $(\mathrm{FC})>1.5$, moderated $t$-test, Software "LIMMA"). Expression differences of all miRNAs were relatively small and did not exceed a 2.3-fold change. miR-142-3p showed a 2.18-fold change (p: 0.0042), miR-144\% a 2.20-fold change (p: 0.0016), miR-21 a 1.67-fold change (p: 0.0089) and let-7c was negatively 1.53 -fold changed (p: 0.0340). Adjusted pvalues of all 22 miRNAs after multiple testing correction did not reach statistical significance (false discovery rate adjusted $\mathrm{p}>0.05$; Table 2). miR-92a was different between the groups but marginally missed the inclusion criteria for the definition of differential expression (cfamiR-92a: p: 0.0359; FC: - 1.45; mmu-miR-92a: p: 0.0422; FC: - 1.41;). However, miR-92a was considered for further analysis (see qPCR). Hierarchical cluster analysis

Table 1 Baseline and clinical characteristics of study population in the control and DCM diseased group

\begin{tabular}{|c|c|c|}
\hline & Control $(n=4)$ & $\mathrm{DCM}(n=4)$ \\
\hline Age (years) & $9.3 \pm 2.1$ & $7.9 \pm 3.3$ \\
\hline Body weight (kg) & $39.3 \pm 8.9$ & $36.6 \pm 4.5$ \\
\hline Gender (male/female) & $2 / 2$ & $3 / 1$ \\
\hline VPCs/24 hours & $12.75 \pm 15.39$ & $2748 \pm 4842^{*}$ \\
\hline $\operatorname{LVEDV}\left(\mathrm{ml} / \mathrm{m}^{2}\right)$ & $67.68 \pm 11.60$ & $120.30 \pm 3.85^{*}$ \\
\hline $\operatorname{LVESV}\left(\mathrm{ml} / \mathrm{m}^{2}\right)$ & $33.63 \pm 7.45$ & $72.50 \pm 2.85^{*}$ \\
\hline EF (\%) & $49.83 \pm 6.37$ & $39.67 \pm 3.68^{*}$ \\
\hline Urea (mmol/l) & $6.00 \pm 0.68$ & $4.80 \pm 1.22$ \\
\hline Creatinine ( $\mu \mathrm{mol} / \mathrm{l})$ & $62.25 \pm 6.40$ & $65.00 \pm 6.58$ \\
\hline cTnl (ng/ml) & $\leq 0.20$ & $0.36 \pm 0.04^{*}$ \\
\hline total RNA (ng/ $\mu \mathrm{l})$ & $3.63 \pm 0.33$ & $4.23 \pm 1.23$ \\
\hline
\end{tabular}

Age, body weight, VPCS, LVEDV, LVESV, EF, urea, creatinine, cTnl and total RNA values in mean $\pm \mathrm{SD}$. $c T n l \leq 0.2$ representing values under the detectable limit. DCM: Dilated cardiomyopathy; VPCs/24 hours: ventricular premature complexes in 24 hours; LVEDV: left ventricular end-diastolic volume; LVESV: left ventricular end-systolic volume; EF: left ventricular ejection fraction; cTnl: cardiac troponin I; RNA: Ribonucleic acid. ${ }^{*} \mathrm{p}<0.05$ vs control. 


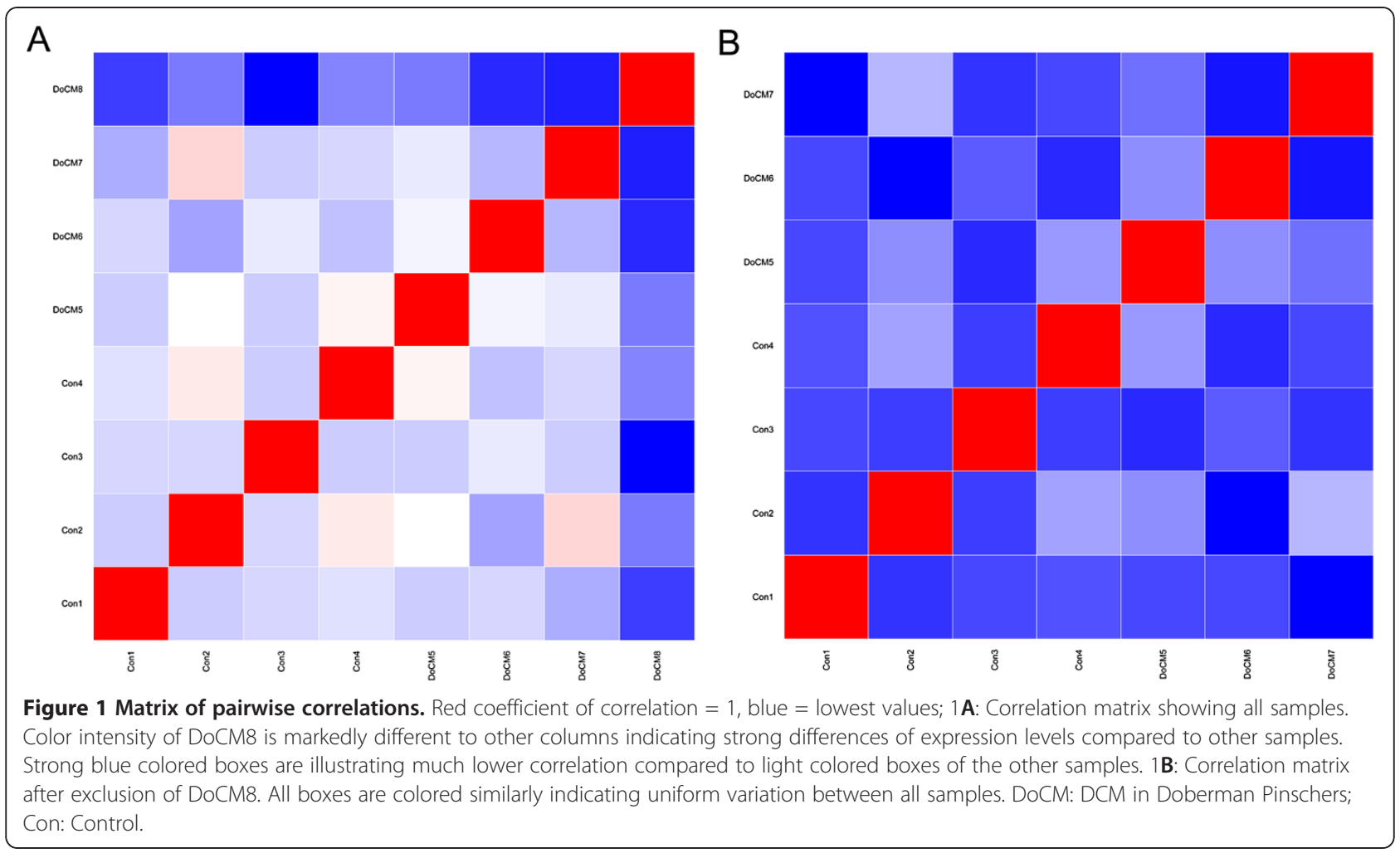

(HCL support tree) is visualizing differences in miRNA patterns between healthy and diseased dogs. This analysis revealed a clear separation of healthy and diseased samples that was stable with 200 iterations as well as relatively high variation within both groups (Figure 3 ).

\section{qPCR}

For further analysis, we selected five miRNAs which have been earlier mentioned in literature as being involved in cardiovascular pathology and which also showed a trend for differential expression in the microarray (miR-142-3p, miR-144*, miR-21, let-7c and miR92a). Five target miRNAs and two endogenous controls were measured by qPCR in the same serum samples used previously for the microarray. The endogenous controls hs_RNU6B_2 and hs_RNU1A_1 did not show a difference in average $\Delta \Delta$ threshold cycle $(\mathrm{Ct})$ between the groups (hs_RNU6B_2: $27.04 \pm 0.62$ vs $27.3 \pm 0.75$; hs_RNU1A_1: $15.72 \pm 0.57$ vs $15.27 \pm 0.94$; mean \pm SD). miR-142-3p and miR-144* showed a trend of upregulation in the diseased group, whereas let-7c was slightly downregulated in DCM dogs. Differences between the groups remained very small. Results showed a high interindividual variance of expression. While the miRNA microarray showed small differences in expression of miR-21 and miR-92a, qPCR revealed almost no differences of these miRNAs between the two groups (Figure 4). With p-values $>0.05$ for all tested target assays, qPCR revealed no statistically significant difference between diseased and healthy dogs (mmu-miR-142-3p: $p=0.771$; mmu-miR-144\%: $\mathrm{p}=0.421$; cfa-let-7c: $\mathrm{p}=0.634$; cfa-miR21: $\mathrm{p}=0.940$; cfa-miR-92a: $\mathrm{p}=0.873$ ).

\section{Discussion}

To date, the role of miRNAs in human DCM has only been studied using cardiac tissue samples [44,48,50,65,66]. These samples are difficult to obtain and studies on circulating serum miRNAs present a much less invasive approach, although the origin and circumstances of miRNA release into the circulation are currently unknown. Myocardium specific miRNAs have been found to be significantly increased in the serum as soon as one hour after myocardial infarction in humans and mice [31,67]. The spontaneous disease model of canine DCM in the Doberman Pinschers may represent a useful target for translational research. We limited the sample volume to approximately $2 \mathrm{ml}$ of whole blood to complete both microarray and qPCR analysis, which can safely be acquired even from small veterinary patients without adverse effects.

According to manufacturer's protocols, most microarray systems require a minimal amount of $100 \mathrm{ng}$ total RNA of each sample to be examined. We used in average $117 \mathrm{ng}$ (84-162 ng) total RNA per sample and more than 400 miRNAs showed a sufficient intensity for evaluation. However, higher RNA concentrations may 


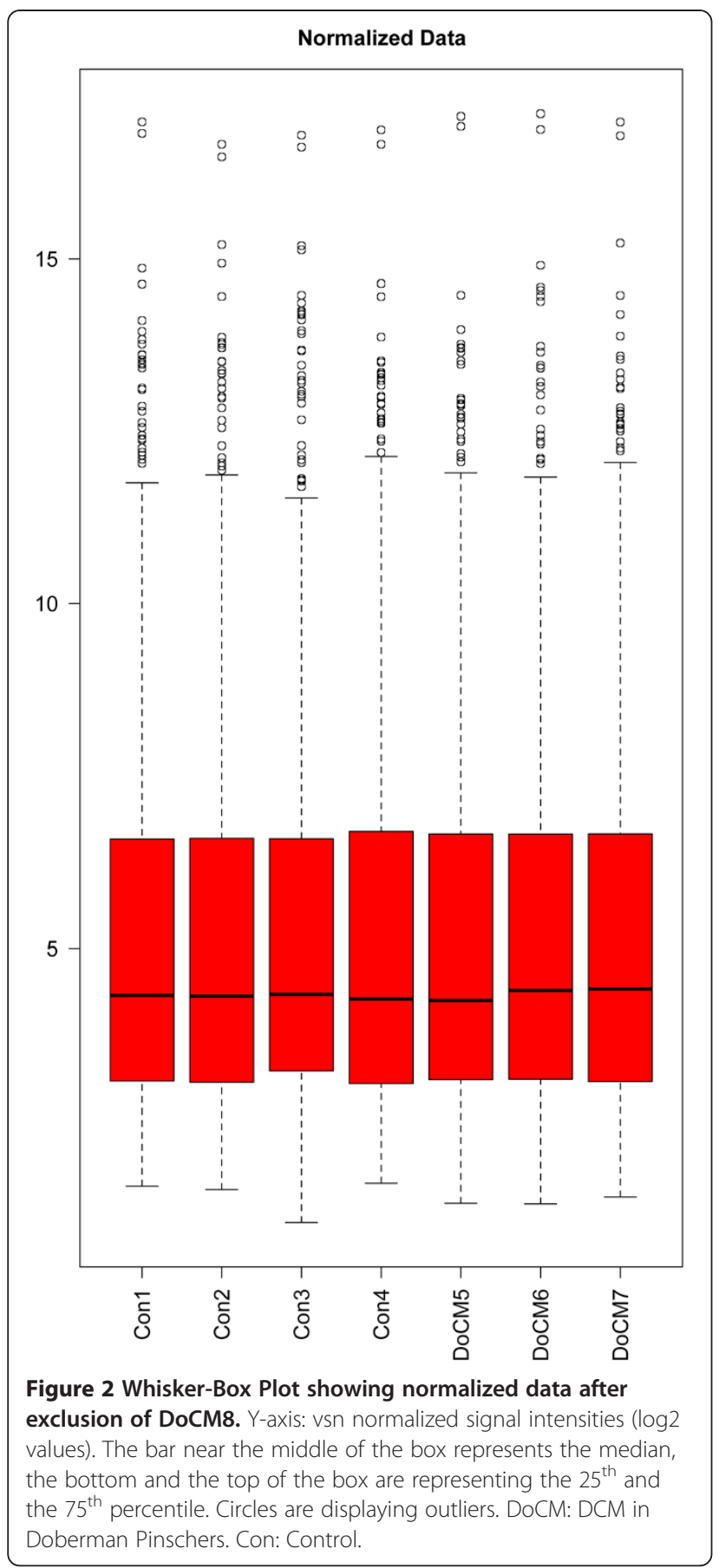

have resulted in more miRNAs to be detected. A standard normalization for miRNA expression analysis of serum samples using microarrays has not been established so far, but normalization of serum volume is reported to be the best method to determine quantity of miRNAs in blood using qPCR [67]. Using the same amount of total RNA in each sample could have produced less interindividual variation in microarray and
Table 2 miRNAs with different expression in the miRNA microarray analysis

\begin{tabular}{|c|c|c|c|}
\hline miRNA & FC & $p$ & $\mathrm{p}$ adjusted \\
\hline mmu-miR-1950 & -2.14 & 0.0225 & 0.6331 \\
\hline mu-miR-744 & -1.87 & 0.0117 & 0.5949 \\
\hline cfa-miR-30c & -1.81 & 0.0141 & 0.5856 \\
\hline mmu-miR-5109 & -1.75 & 0.0185 & 0.5903 \\
\hline mmu-miR-423-3p & -1.74 & 0.0043 & 0.5558 \\
\hline mmu-miR-5115 & -1.66 & 0.0110 & 0.5856 \\
\hline cfa-miR-376a & -1.62 & 0.0141 & 0.5968 \\
\hline mmu-miR-1968 & -1.58 & 0.0251 & 0.6331 \\
\hline cfa-miR-188 & -1.57 & 0.0365 & 0.6405 \\
\hline mmu-miR-18a* & -1.56 & 0.0159 & 0.6093 \\
\hline cfa-let-7c & -1.53 & 0.0340 & 0.6331 \\
\hline mmu-miR-32 & 1.50 & 0.0476 & 0.6468 \\
\hline cfa-let-7f & 1.53 & 0.0130 & 0.5968 \\
\hline mmu-miR-3104-3p & 1.59 & 0.0226 & 0.6331 \\
\hline mmu-miR-5124 & 1.65 & 0.0468 & 0.6399 \\
\hline cfa-miR-21 & 1.67 & 0.0089 & 0.5856 \\
\hline cfa-miR-101 & 1.68 & 0.0402 & 0.6331 \\
\hline mmu-miR-101c & 1.70 & 0.0394 & 0.6331 \\
\hline mmu-miR-5136 & 1.82 & 0.0409 & 0.6331 \\
\hline mmu-miR-144 & 2.02 & 0.0067 & 0.5640 \\
\hline mmu-miR-142-3p & 2.18 & 0.0042 & 0.5640 \\
\hline mmu-miR-144* & 2.20 & 0.0016 & 0.5476 \\
\hline
\end{tabular}

$\mathrm{p}<0.05, \mathrm{FC}>1.5$; $\mathrm{p}$ adjusted with FDR. FC: fold change, FDR: false discovery rate, cfa: canis familiaris, mmu: mus musculus, miR: microRNA.

PCR analysis and should be investigated in further experiments.

We excluded one sample of the diseased group from further analysis of microarray data since miRNA expression levels were extremely different to others even after normalization. This sample was taken from a young dog and had the longest storage time. Total RNA yield from this sample was very low compared to the other samples, whereas signals of miRNAs were intensified in this sample. Patient age is described not to influence miRNA levels in plasma [25] and miRNAs are claimed to be robust against long freezing time [24,68]. Reasons for the difference of this sample remain unexplained.

Since the miRNA database contains more murine and human miRNAs than canine sequences we chose to use both canine and murine targets for our microarray. Sequences have been found to be highly conserved among species with many mature miRNA sequences displaying $100 \%$ homology $[36,61,63]$. The microarray results confirm that canine miRNAs hybridize with multiple murine targets, which facilitates studies using veterinary samples. The phylogenetic relationship of mouse, dog and human is a matter of debate and not unequivocally determined 


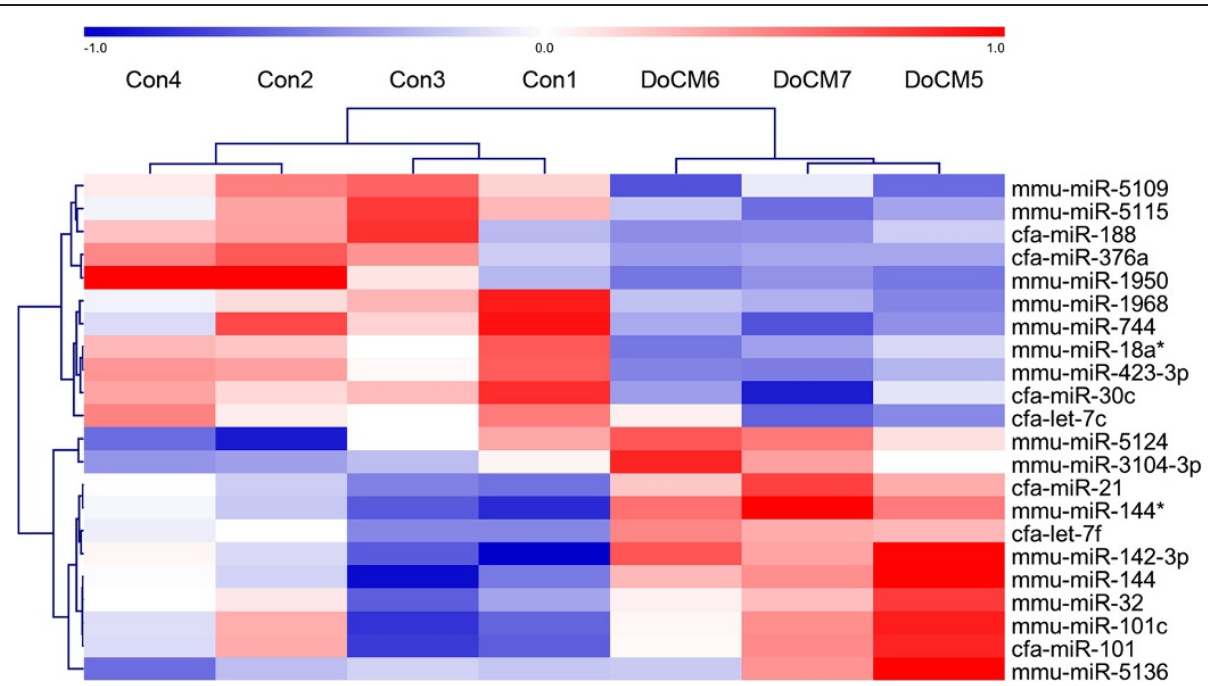

Figure 3 Hierarchical cluster analysis (HCL support tree) summarizing miRNA expression differences. Each column represents 1 of 7 samples, each row represents 1 of 22 miRNAs with nominal p-values $<0.05$. Samples were reproducibly grouped in DoCM and controls after unsupervised hierarchical clustering (MeV 4.7.1, Pearson correlation, HCL support tree, 200 iterations). The different colors of the tree visualize the reliability of branching (black: 100\%, grey: 90-100\%, blue: 80-90\%, green: 70-80\%, yellow: 60-70\%, ocher: 50-60\%, magenta: 0-50\%, red: 0\% support). Red and blue (rectangles) indicating higher and lower expression levels, respectively, relative to the mean of all samples (log2 meancentered expression values); DoCM: Dilated Cardiomyopathy in Doberman Pinschers; Con: Control; cfa: canis familiaris, mmu: mus musculus, miR: microRNA.

$[69,70]$. Homology in coding genes might not reflect the situation of noncoding DNA, some miRNA clusters have been found to be unique to primates. In a pilot study we tested mouse serum as positive controls for qPCR detection of several miRNAs vs canine serum and detected the same PCR products in both samples using murine assays.
Notably for miRNA studies of cardiac tissue, more information is available for murine samples, including studies on knockout mice. Additionally, a recent analysis of the heart transcriptome shows a higher similarity between dog and mouse than between dog and human [71]. As stated in the manuscript it cannot be ruled out that some murine

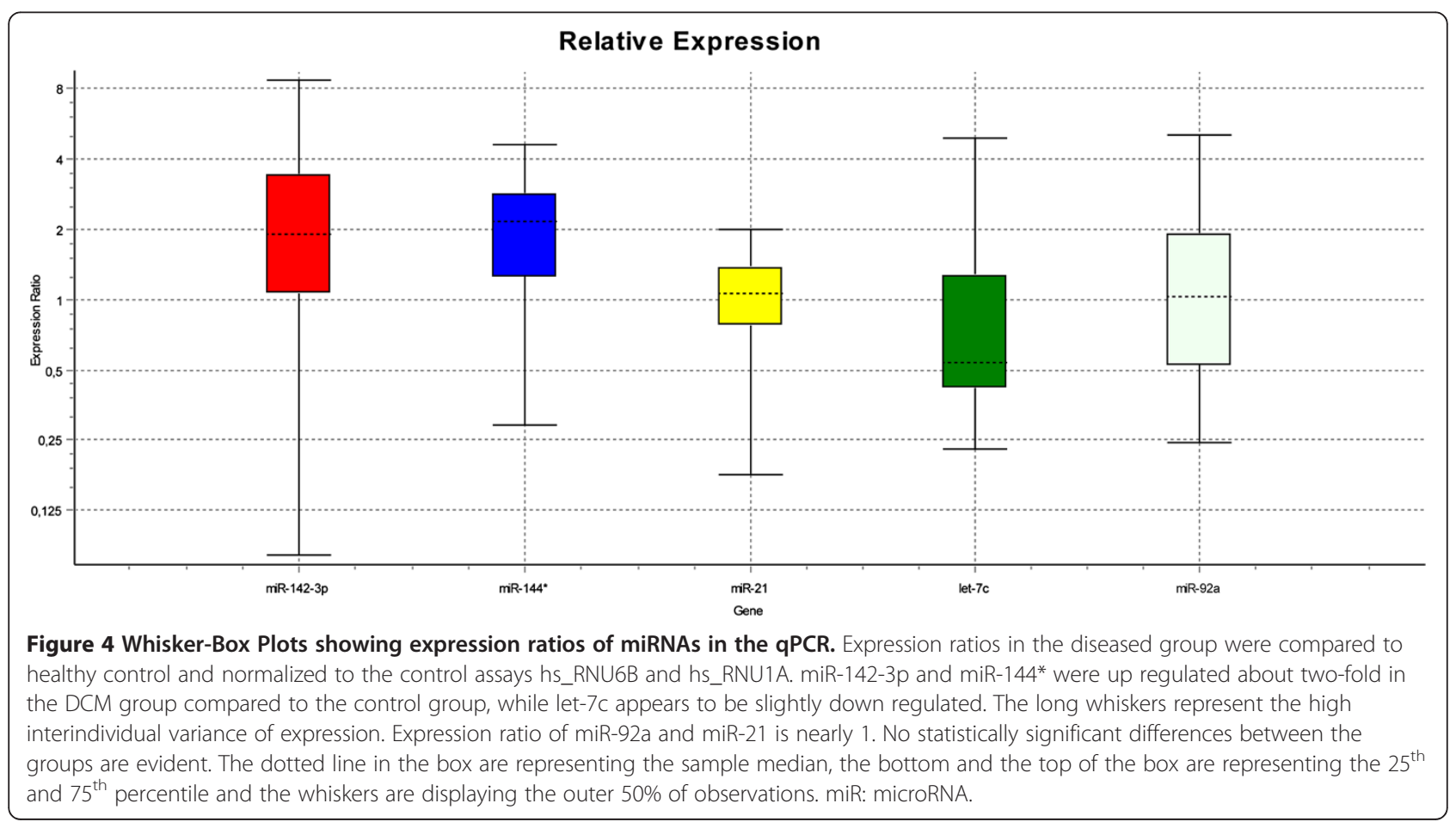


probes on the array do not match the canine miRNAs, but this would also be the case for human probes. Whether human or murine miRNAs as a whole are more closely related to dog miRNAs and which one would be the better' model so far remains an open question.

In our study, the differences in miRNA expression between the two groups were not large and consistent enough to reach statistical significance when the results were adjusted for multiple testing. Although single miRNAs were not statistically significant between the two groups, hierarchical cluster analysis of several miRNAs showed a clear separation of diseased and control samples and enabled a reliable differentiation between healthy and diseased dogs. Therefore, a combined expression analysis of several miRNAs may be a new diagnostic tool for the detection of DCM in Doberman Pinschers and should be further investigated in future studies. This study with its comparatively small patient cohort should be considered as a pilot study requiring confirmation and validation of results in larger sample groups.

A microarray study comparing miRNA expression in heart tissue samples from several human heart diseases revealed let-7c to be significantly upregulated and miR101 to be significantly downregulated in human DCM, although the changes were less than two-fold [48]. In contrast, our study detected a downregulation of let-7c and an upregulation of miR-101, but the changes were quite subtle.

The let-7 family has been shown to be one of the most abundant miRNAs in murine heart tissue [46]. Recently, a decrease of myocardial let-7i was associated with severity of left ventricular dysfunction and poor clinical outcome in human DCM patients and therefore supposed to be a potential prognostic marker [50]. Let-7i was reported to target for toll-like receptor 4 (TLR4) in vitro, a critical transcription factor in the myocardium of DCM in humans [72,73]. In the presented study of canine DCM of Doberman Pinschers, expression changes of let-7i were not evident, but it is not known to date whether TLR4 is a critical transcription factor in canine DCM.

miR-101 has been addressed in several studies as a potent tumor suppressor and inhibitor of autophagy and is obviously expressed in many different tissues [74,75]. A specific regulating effect on the cardiovascular system has not been detected to date.

miR-21 is universally expressed in various organs like spleen, small intestine, colon and the heart [36]. Several studies demonstrated the overexpression of miR-21 in tumor tissues [76,77]. It is also highly expressed in vascular smooth muscle cells, endothelial cells, cardiomyocytes and cardiac fibroblasts [66,78-81]. Deregulated expression of miR-21 has been described for proliferative vascular disease, cardiac hypertrophy, heart failure and ischemic heart disease [44,78,80,82-85]. Myocardial degeneration with cardiac fibrosis and myointimal hyperplasia of the coronary vessels are common histologic findings in the DCM of Doberman Pinschers $[6,10,86,87]$. miR-21 is upregulated during cardiac remodeling in response to cardiac stress and leads to fibroblast proliferation and fibrosis in humans [66,88]. In the Doberman Pinschers suffering from DCM, miR-21 appeared to be slightly upregulated in the microarray, but the trend could not be confirmed using qPCR assays. In human DCM heart tissue samples, one study group found a subtle and non-significant downregulation of miR-21 [48], while another study claimed miR-21 to be significantly upregulated about two-fold compared to healthy controls [50]. Recently, experimental studies demonstrated an increase of miR-21 expression in right ventricular cells induced by drug therapy. Due to the increase of miR-21, right ventricular function during right heart failure improved as well [89].

In miRNA microarray, miR-92a was slightly downregulated in DCM diseased Doberman Pinschers, but this could not be confirmed using the qPCR assay. As mentioned above, a related miRNA, miR-92, was shown to be downregulated in human DCM tissues [48,49]. Overexpression of miR-92a inhibits angiogenesis in ischemic myocardial tissues in mice and is involved in the control of cardiomyocyte survival. Experiments of external inhibition of miR-92a led to improved left ventricular function [90]. Since all of the diseased dogs received positive inotropic therapy (Pimobendan), this may influence miR92a expression. So far, very little is known about the effects of cardiovascular therapy on miRNA expression.

For $\mathrm{miR}-142-3 \mathrm{p}$ and $\mathrm{miR}-144^{*}$, we found a trend for upregulation in DCM diseased dogs both in the microarrays and the qPCR results, although interindividual variation was very high. miR-144 was also upregulated in the microarray analysis. miR-144 and miR-144* are the two strands of the double stranded precursor miRNA (mir-144). miR-144 is known to be expressed in a cluster with miR-451. The miR-144/451 promoter is activated by GATA-4, a critical transcription factor in the heart. Both partners of the cluster are supposed to confer protection against stimulated ischemia/reperfusion-induced cardiomyocyte death and may therefore represent possible therapeutic agents for the treatment of ischemic heart disease in humans [91]. The left ventricular dilation, which is a characteristic sign of DCM, leads to myocardial stress. The upregulation of miR-144 might be a stress response of affected myocytes and an attempt to protect the cells against this stimulus. Recruitment of a larger canine patient cohort may allow further validation of these findings.

In accordance with our findings, miR-142-3p has been shown previously to be upregulated in human patients 
with chronic heart failure caused by nonischemic DCM [52]. This miRNA is one of five negatively regulating cardiac hypertrophy in recent experimental models. Therefore, miR-142-3p is currently discussed as a part of potential therapeutic targets for the treatment of cardiac hypertrophy [92].

The mechanism and exact circumstances of miRNA release into the serum are not fully understood to date [27]. Protected by protein-bound complexes or incorporated into lipid carriers, miRNAs are resistant to RNases in circulation. It is estimated that about $80 \%$ of circulating miRNAs are secreted in protein complexes. The other part of circulating miRNAs is released in membranebound vesicles (apoptotic bodies, microvesicles, exosomes) [93-97]. It is suspected that the release of miRNAs into the circulation occurs selectively and the existence of a specific packaging mechanism is therefore suggested. For example, in a metastatic gastric cancer cell line, members of the let- 7 family are selectively released into the circulation [98]. Similarly, different human cell lines secrete certain miRNAs upon serum deprivation as part of a stress response [93]. The correlation between circulating and tissue miRNA expressions is still controversial. Diseased cells might not be the only origin of changes in circulating miRNAs. It is also possible that currently unknown signals, e.g. stress signals, are sent from the diseased tissue to other organs in the body and cause a specific release of miRNAs into the circulation. Several experimental studies have suggested that circulating miRNAs can be transferred to target cells and regulate gene expression $[99,100]$. Circulating miRNA expression patterns might therefore differ from expression patterns extracted from the diseased organ itself. This could explain the discrepancies of circulating miRNA expression patterns found in this study to cellular miRNA expression patterns found in other studies.

All dogs in the DCM group received a background therapy consisting of ACE-Inhibitors and Pimobendan and either Sotalol or Amiodarone as antiarrhythmic therapy. It is possible that medication did not only improve cardiac abnormalities but also influenced miRNA expression changes. The elevated cTnI levels of diseased dogs in this study reflect ongoing myocardial injury. Studies comparing circulating miRNA expression in different disease stages of DCM are needed to verify temporal changes in the course of this disease. No studies are published about a possible influence of the drugs used to treat the dogs in this study on the miRNA expression. For the purpose of this study only dogs with unequivocal echocardiographic in addition to unequivocal electrocardiographic changes were selected. Therefore, only patients in advanced disease stages were selected and it would have been unethical not to treat those dogs. All dogs received the same background therapy (Pimobendan and ACE-inhibitors), but antiarrhythmic therapy was individualized [15,101]. Antiarrhythmic therapy was adjusted according to the patient's individual electrocardiographic changes and was therefore not completely homogenous. In some cases, antiarrhythmic therapy was changed in later visits (after serum sampling) because of inadequate response to the administered medication (change from Sotalol to Amiodarone, combination of Amiodarone and Mexiletin or combination of Sotalol and Mexiletin).

\section{Conclusions}

In conclusion, this study demonstrates that miRNA expression profiling is technically feasible in a clinical setting, revealing its potential as a possible new diagnostic approach in veterinary medicine. Standardized protocols for normalization and larger group sizes for different diseases are needed to confirm whether circulating miRNAs may serve as biomarkers in dogs in the future and whether canine disease models display changes similar to human heart diseases.

\section{Methods}

\section{Ethic statement}

The dogs in this study were examined during preventive diagnostic procedures with the written consent of their owners (to participate in a study in which remaining blood samples not used for necessary diagnostic procedures are stored and used for genetic, miRNA and other diagnostic research procedures). All local regulations (Germany) were strictly observed. The study was approved by the University of Munich Committee on Research Ethics. There is no permit number as this study is not based on an invasive animal experiment. The data were obtained during routine diagnostic procedures. As the data are from client-owned dogs that underwent normal veterinary exams, there was no "animal experiment" according to the legal definitions in Germany. Nonetheless, the study was reviewed and approved by the local ethics review boards.

\section{Study population}

Eight purebred Doberman Pinschers were retrospectively selected from a large study cohort of the LudwigMaximilians-Universität München (LMU Munich) with a longitudinal study design starting in 2004. Each examination included a questionnaire completed by the owner, recording of body weight, physical examination, short-time electrocardiogram (ECG), Holter monitoring and echocardiography. Echocardiography included MMode and Simpson's method of disc measurements as well as color and spectral Doppler measurements. Venous blood was collected from each patient for screening of serum parameters and the samples were stored for further analysis with the owner's consent. We included 
only purebred Doberman Pinschers without evidence of systemic disease. Exclusion criteria were evidence of concomitant congenital heart diseases or mitral valvular disease in echocardiography. We retrospectively chose eight dogs which met selection criteria of groups as defined below.

\section{ECG}

Dogs were positioned in right lateral recumbency. ECG was performed according to standard technique with a twelve channel ECG machine (Schiller Cardiovit AT-10, SCHILLER Medizintechnik GmbH, Germany). Electrical activity was recorded for about 30 seconds and printed for evaluation of any electrical abnormalities. A concurrent ECG was recorded during echocardiography without getting printed.

\section{Echocardiography}

Echocardiography was performed without sedation in right and following left lateral positions. Examinations were performed with a high frame rate ultrasound system with 2.0/4.3 MHz probes and simultaneous ECG recordings (Vivid 7 dimension, General Electric Medical System, Waukesha, WI). Simpson's method of disc measurements were recorded in right parasternal long-axis and left apical four chamber views. All valves were examined by color Doppler technique. Spectral Doppler was used for velocity measurement over the aortic and pulmonic valves and had to reveal no evidence of abnormalities.

\section{Holter examinations}

Holter monitoring was performed following echocardiography. The electrical activity was recorded for 24 hours in the normal environment of the dogs without clinical habitation. Monitor was removed after 24 hours and commercially available Holter analysis systems were used for analysis of the digitally recorded ECGs (Custo tera, Arcon Systems GmbH, Starnberg, Germany; Amedtech ECGpro Holter software, EP 810 digital recorder, Medizintechnik Aue $\mathrm{GmbH}$, Aue, Germany). Manual adjustments and verification of accuracy of systemically detected arrhythmias were performed by veterinarians with experience in Holter analysis. Total numbers of VPCs were tabulated.

\section{Blood preparation}

Blood (5 ml) was drawn from jugular vein of each patient and allowed to clot at room temperature for at least 20 minutes. The sample was centrifuged at $600 \mathrm{~g}$ RCF for five minutes at room temperature and the serum was transferred to $0.5 \mathrm{ml}$ polypropylene tubes (Eppendorf, Hamburg, Germany) and stored at $-80^{\circ} \mathrm{C}$ until RNA isolation.
Four dogs each were grouped into two different groups according to the results of the electrocardiographic and echocardiographic examination:

- Control group: Dogs in this group had an age of seven years or older and no clinical signs of systemic or cardiac disease. Renal parameters had to be in the reference range (Urea: $3.3-8.3 \mathrm{mmol} / \mathrm{l}$, Creatinine: $31.8-117 \mu \mathrm{mol} / \mathrm{l}$ ) and $\mathrm{cTn}$ I levels had to be $\leq 0.2$ $\mathrm{ng} / \mathrm{ml}$. There were no electrical abnormalities in the ECG: all amplitudes, duration of PQ-interval and mean electrical axis were in normal ranges, dogs had $<50$ VPCs in the Holter examination.

Echocardiographic measurements were considered to be normal. This includes no or only trivial insufficiencies of the valves. Simpson's method of disc was used for calculation of the left ventricular end-diastolic (LVEDV) and end-systolic (LVESV) volume normalized to the body surface area (BSA). LVEDV/BSA $\leq 100 \mathrm{ml} / \mathrm{m}^{2}$ and LVESV/BSA $\leq 55$ $\mathrm{ml} / \mathrm{m}^{2}$ were considered as normal [102]. The ratio of the left atrium to the aorta (LA/Ao) was 1.5 or less. We are in frequent communication by phone with all owners. We perform yearly screenings to monitor healthy dogs and to detect even early changes. All healthy dogs are alive and healthy at the time of reviewing this paper. We already performed follow-up evaluations in 2012 and could not detect any evidence of DCM in these dogs.

- DCM group (occult stage): Dogs in this group had no clinical signs of systemic disease. Owners did not observe any events of syncope or exercise intolerance. Clinical signs of cardiovascular abnormalities (pale mucosal color, weak pulse, pulse deficit or arrhythmic pulse, heart murmur) were acceptable. Renal parameters had to be in reference range and circulating $\mathrm{cTn}$ I levels were elevated (>0.2 ng/ml). Electrical and morphological abnormalities existed in the current visit or in one of the earlier visits (partly normal under therapy in the current visit): Dogs had > 100 VPCs in the Holter examination and echocardiographic changes including LVEDV/BSA > $100 \mathrm{ml} / \mathrm{m}^{2}$ and LVESV/ BSA $>55 \mathrm{ml} / \mathrm{m}^{2}$ [102]. LA/Ao had to be 1.5 or less. We performed frequent control examinations every $1-6$ months to monitor development of disease. After the diagnosis of DCM, we performed $4-6$ follow-up examinations of dogs in this group. The time course of electrocardiographic and echocardiographic changes is listed in Table 3. Due to the severe existing changes, all dogs received therapy at the time of serum sampling. Dosing of drugs was standardized. Further characteristics of diseased dogs are listed in Table 4. 
Table 3 Time course of electrocardiographic and echocardiographic changes of dogs with DCM starting from time of diagnosis

\begin{tabular}{|c|c|c|c|c|c|c|}
\hline Sample name & Number of visits & VPCs/24 hours & Maximal velocity of VPCs (bpm) & LVEDV $\left(\mathrm{ml} / \mathrm{m}^{2}\right)$ & LVESV $\left(\mathrm{ml} / \mathrm{m}^{2}\right)$ & EF (\%) \\
\hline \multirow[t]{4}{*}{ DoCM 5} & $1^{\text {st }}$ visit & 254 & 240 & 119.20 & 65.80 & 44.67 \\
\hline & $2^{\text {nd }}$ visit & 107 & 203 & 94.60 & 56.70 & 40.08 \\
\hline & $3^{\text {rd }}$ visit* & 161 & 200 & 116.80 & 73.10 & 37.41 \\
\hline & $4^{\text {th }}$ visit & 199 & 214 & 110.90 & 62.40 & 43.72 \\
\hline \multirow[t]{6}{*}{ DoCM 6} & $1^{\text {st }}$ visit & 13641 & 300 & 105.70 & 63.40 & 39.97 \\
\hline & $2^{\text {nd }}$ visit & 10355 & 319 & 124.20 & 79.40 & 36.06 \\
\hline & $3^{\text {rd }}$ visit* & 10005 & 300 & 122.50 & 68.40 & 44.21 \\
\hline & $4^{\text {th }}$ visit & 14 & 196 & 112.30 & 77.60 & 30.93 \\
\hline & $5^{\text {th }}$ visit & 22 & 230 & 132.50 & 78.20 & 41.01 \\
\hline & $6^{\text {th }}$ visit & 24 & 300 & 142.50 & 94.50 & 33.73 \\
\hline \multirow[t]{6}{*}{ DoCM 7} & $1^{\text {st }}$ visit & 1940 & 230 & 112.70 & 72.90 & 35.31 \\
\hline & $2^{\text {nd }}$ visit & 2478 & 275 & 121.70 & 82.40 & 32.31 \\
\hline & $3^{\text {rd }}$ visit & 17 & 273 & 116.40 & 79.90 & 31.40 \\
\hline & $4^{\text {th }}$ visit $^{*}$ & 616 & 180 & 117.30 & 75.00 & 36.04 \\
\hline & $5^{\text {th }}$ visit & 3010 & 250 & 151.20 & 108.50 & 28.24 \\
\hline & $6^{\text {th }}$ visit & 135 & 300 & 143.70 & 123.30 & 14.19 \\
\hline \multirow[t]{4}{*}{ DoCM 8} & $1^{\text {st }}$ visit & 302 & 300 & 116.00 & 72.30 & 37.68 \\
\hline & $2^{\text {nd }}$ visit & 9 & 265 & 109.90 & 59.80 & 45.62 \\
\hline & $3^{\text {rd }}$ visit* & 209 & 202 & 124.60 & 73.50 & 41.01 \\
\hline & $4^{\text {th }}$ visit & 7295 & 300 & 99.00 & 50.50 & 48.93 \\
\hline
\end{tabular}

DCM: Dilated cardiomyopathy, DoCM: Dilated Cardiomyopathy in Doberman Pinschers, VPCs: Ventricular premature complexes, VPCs/24 hours: ventricular premature complexes in 24 hours; bpm: beats per minute; LVEDV: left ventricular end-diastolic volume; LVESV: left ventricular end-systolic volume; EF: left ventricular ejection fraction, *: visit of serum sampling for microRNA analysis.

\section{RNA extraction}

Total RNA was isolated using the miRNeasy Mini Kit (QIAGEN, Valencia, CA, USA) according to the supplementary protocol "Purification of total RNA, including small RNAs, from serum or plasma using the miRNeasy Mini Kit”. Briefly, $400 \mu$ serum were mixed with $2 \mathrm{ml}$ of QIAzol Lysis Reagent and $400 \mu$ Chloroform. The sample was centrifuged and the upper aqueous phase was transferred to a collection tube and mixed with $975 \mu \mathrm{l}$ $100 \%$ ethanol. The mixture was applied to RNeasy Mini spin columns and purified according to the protocol. Total RNA was eluted using $50 \mu \mathrm{l}$ of RNAse free water. RNA concentrations were determined using a NanoDrop ND-1000 spectrophotometer (NanoDrop Technologies, Wilmington, DE, USA). Samples were stored at $-80^{\circ} \mathrm{C}$.

\section{miRNA microarray}

The miRNA Microarray System with miRNA Complete Labeling and hybridization Kit (Agilent Technologies) was used according to the manufacturer's recommended protocol. The Agilent microRNA Spike-In Kit was used for in-process control to measure labeling and hybridization efficiency. The RNA samples were dried in a Vacuum Contractor (Bachofer Plumbing Heating \&
Air Conditioning, Salina, KA, USA) for one hour. All samples were dephosphorylated by incubation with calf intestinal phosphatase at $37^{\circ} \mathrm{C}$ in a heat block for 30 minutes and incubated in $100 \%$ DMSO at $100^{\circ} \mathrm{C}$ for seven minutes for denaturation. All samples were labeled with pCp-Cy3 using $\mathrm{T} 4$ ligase by incubation at $16^{\circ} \mathrm{C}$ for two hours. Micro Bio-Spin 6 chromatography columns (Bio-Rad Laboratories, Hercules, CA, USA) were used for purification of the labeled RNA. After drying the samples completely, samples were prepared for hybridization by adding nuclease-free water, Hyb Spike-In solution, 10X GE Blocking Agent and 2X Hi-RPM Hybridization Buffer. Samples were hybridized to a custom-designed $8 \times 60 \mathrm{k}$ Agilent microarray. The custom microarray covered all murine and canine miRNAs from miRBASE version 17.0 [103] and contained probes for 1386 individual miRNAs with each miRNA covered by 40 different features. Hybridizations were performed in hybridization chambers (Agilent) for 20 hours at $55^{\circ} \mathrm{C}$ and the slides were washed as described in the protocol. Arrays were scanned at a resolution of $2 \mu \mathrm{m}$ using an Agilent G2505C Scanner. The microarray data discussed in this publication have been deposited in NCBIs Gene Expression Omnibus 
Table 4 Further characteristics of DCM diseased dogs

\begin{tabular}{|c|c|c|c|c|c|c|}
\hline $\begin{array}{l}\text { Sample } \\
\text { name }\end{array}$ & $\begin{array}{l}\text { Age of } \\
\text { diagnosis of } \\
\text { DCM (years) }\end{array}$ & $\begin{array}{l}\text { Age at the date of } \\
\text { serum sampling } \\
\text { (years) }\end{array}$ & $\begin{array}{l}\text { Time of treatment } \\
\text { prior to serum } \\
\text { sampling (days) }\end{array}$ & $\begin{array}{l}\text { Drug therapy administered } \\
\text { until the time of serum } \\
\text { sampling }\end{array}$ & Outcome & $\begin{array}{l}\text { Age at the time } \\
\text { of death (years) }\end{array}$ \\
\hline DoCM 5 & 11.2 & 11.5 & 140 & $\begin{array}{l}\text { Pimobendan, ACE Inhibitor, } \\
\text { Sotalol }\end{array}$ & $\begin{array}{l}\text { Other systemic disease } \\
\text { (gastric volvulus) }\end{array}$ & 11.9 \\
\hline DoCM 6 & 7.5 & 7.8 & 119 & $\begin{array}{l}\text { Pimobendan, ACE Inhibitor, } \\
\text { Amiodarone }\end{array}$ & Sudden cardiac death & 8.6 \\
\hline DoCM 7 & 7.4 & 8.5 & 397 & $\begin{array}{l}\text { Pimobendan, ACE Inhibitor, } \\
\text { Sotalol }\end{array}$ & $\begin{array}{l}\text { Euthanasia because of } \\
\text { non-responsive congestive } \\
\text { heart failure }\end{array}$ & 9.2 \\
\hline DoCM 8 & 3.0 & 3.6 & 321 & $\begin{array}{l}\text { Pimobendan, ACE Inhibitor, } \\
\text { Amiodarone* }\end{array}$ & $\begin{array}{l}\text { Euthanasia because of } \\
\text { non-responsive congestive } \\
\text { heart failure }\end{array}$ & 4.3 \\
\hline
\end{tabular}

DoCM: Dilated Cardiomyopathy in Doberman Pinschers. ACE: Angiotensin Converting Enzyme. *: The medication was not consistently administered because of incompliance of the owner.

(GEO, http://www.ncbi.nlm.nih.gov/geo/) and are accessible through GEO Series accession number GSE36976.

\section{Microarray data analysis}

Feature Extraction Software Version 10.7.3.1. was used for grid alignment and data extraction. Signal intensities for each feature were scanned and calculated by subtracting the background. The flag "is well above background" (WABG) produced by the Feature Extraction Software was used to filter signals above background noise. Features had to contain a minimum of two WABG flags "1" in at least one of the experimental groups (detectable in at least two samples of the control or the DCM group) to be included in the further analysis. Mean signal intensities were calculated for each detectable miRNA probe and subsequently normalized between samples using the BioConductor package "vsn" [104]. For quality control, normalized data were analyzed with a heatmap based on pair-wise distances (BioConductor package geneplotter). Software "LIMMA“(Bioconductor) [105] was used for significance analysis (function "decideTests") and assessment of miRNA expression changes.

\section{Quantitative real-time RT-PCR (qPCR)}

After total RNA purification, reverse transcription was performed using the miScript Reverse Transcription Kit (Qiagen) according to manufacturer's protocol. The miScript SYBR Green PCR Kit (Qiagen) was used for qPCR according to the manufacturer's protocol. The miScript Primer Assays cf_miR-92a_1, mm_miR-1423p_1, cf_let-7c_1, mm_miR_144:_1 and $c f_{-} m i R-21 \_1$ were used as target miRNAs. hs_RNU6B_2 and hs_RNU1A_1 were used as endogenous control assays. All samples were run as duplicates. To account for spurious PCR amplification of contaminating genomic DNA, a control containing total RNA without reverse transcription was included. As negative controls, the amplification mixture of each assay was run without adding the reverse transcribed RNA. Relative quantification was carried out using the $\Delta \Delta$ threshold cycle $(\mathrm{Ct})$ method with hs_RNU6B_2 and hs_RNU1A_1 as endogenous controls. The TaqMan 7500 Real Time PCR System (Applied Biosystems, Life Technologies Corporation, Carlsbald, CA, USA) was used for qPCR.

\section{Statistical analysis Study population}

The software GraphPad Prism version 5.04 for Windows (GraphPad Software, La Jolla, CA) was used for statistical analysis of the cohort. Mann-Whitney one-way test was used to calculate differences for all parameters in Table 1.

\section{miRNA microarray}

A "moderated $t$-test" (Software "LIMMA") was used for statistical analysis of the mean miRNA expression differences in the miRNA microarray. Multiple testing correction was performed using the parameter "FDR" (false discovery rate) in the function "decideTests" for adjustment of p-values. A p-value $<0.05$ was considered to be statistically significant. FC was calculated (Software "LIMMA") and included into the assessment of expression ratios (FC at least 1.5-fold was considered to be significant). Software program Multi Experiment Viewer ( $\mathrm{MeV}$ v.4.7.1) was used for hierarchical clustering of 22 different miRNAs using HCL support trees, Pearson correlation and 200 iterations.

\section{$q P C R$}

Target assays were normalized to internal controls hs_RNU6B_2 and hs_RNU1A_1 which had been found to be suitable as controls in dog serum in a preliminary test. The software "REST 2009" was used for analysis of relative expression in PCR assays [106,107]. Mean values 
of twice prepared approaches were used. A p-value $<0.05$ was considered to be statistically significant.

\section{Abbreviations}

BSA: Body surface area; Ct: Threshold cycle; CTnl: Cardiac Troponin I; DCM: Dilated cardiomyopathy; ECG: Electrocardiogram; EF: Ejection fraction; FC: Fold change; FDR: False discovery rate; Holter: 24-hour ambulatory electrocardiogram; ICM: Ischemic cardiomyopathy; LA/Ao: Ratio of the left atrium to the aorta; LVEDV: Left ventricular end-diastolic volume; LVESV: Left ventricular end-systolic volume; miRNA: MicroRNA; qPCR: Real-Time RT-PCR; VPC(s): Ventricular premature contraction(s); WABG: Well above background.

\section{Competing interest}

The authors declare that they have no competing interests.

\section{Authors' contributions}

CS, KW and GW designed the study. GW carried out and CS participated in all patient examinations, classified groups and collected material. CS and KW carried out all laboratory procedures. SB and KW designed the miRNA microarray, SB participated in the microarray procedure, analyzed data and performed statistical analysis. CS drafted the manuscript. KW, GW and SB helped to enhance the manuscript. All authors read and approved the final manuscript.

\section{Authors' information}

Carola Steudemann (CS), DVM, Clinic of Small Animal, LMU University of Munich

Dr. rer. nat. Stefan Bauersachs (SB), team leader, Functional Genomics of Reproduction, Genomics Unit, Laboratory of Functional Genome Analysis, Gene Center, LMU University of Munich

Dr. med. vet. Karin Weber (KW), DVM, specialist for veterinary physiology, head of laboratory diagnostics and molecular biology, Clinic of Small Animal, LMU University of Munich

PD, Dr. med. vet., Dr. vet. med. habil. Gerhard Wess (GW), DVM, Dipl. ACVIM (Cardiology), Dipl. ECVIM-CA (Cardiology and Internal Medicine), head of cardiology service, Clinic of Small Animal, LMU University of Munich.

\section{Availability of Supporting Data}

Supporting data has been deposited in NCBls Gene Expression Omnibus (GEO, http://www.ncbi.nlm.nih.gov/geo/) and is accessible through GEO Series accession number GSE36976.

\section{Acknowledgments}

We would like to thank Anastazia Samborski for her excellent technical support. The authors also acknowledge the assistance of the faculty, staff, clinicians and pet owners that participated in the study.

\section{Author details}

'Clinic of Small Animal Medicine, LMU University of Munich, Veterinaerstrasse 13, Munich 80539, Germany. ${ }^{2}$ Laboratory for Functional Genome Analysis (LAFUGA), Gene Center, LMU University of Munich, Feodor-Lynen-Strasse 25, Munich 81377, Germany.

Received: 11 July 2012 Accepted: 14 January 2013

Published: 17 January 2013

\section{References}

1. O'Grady MR, O'Sullivan ML: Dilated cardiomyopathy: an update. Vet Clin North Am Small Anim Pract 2004, 34(5):1187-1207.

2. Tidholm A, Haggstrom J, Borgarelli M, Tarducci A: Canine idiopathic dilated cardiomyopathy. Part I: aetiology, clinical characteristics, epidemiology and pathology. Vet J 2001, 162(2):92-107.

3. Vollmar AC: The prevalence of cardiomyopathy in the Irish wolfhound: a clinical study of 500 dogs. J Am Anim Hosp Assoc 2000, 36(2):125-132.

4. Calvert CA, Meurs KM: Cardiomyopathy in doberman pinschers. In Kirk's Current Veterinary Therapy XIV. vol. XIVth edition. Edited by Bonagura JD, Twedt DC. St. Louis: Saunders Elsevier; 2009:800-803.

5. Calvert $C A$, Brown J: Influence of antiarrhythmia therapy on survival times of 19 clinically healthy doberman pinschers with dilated cardiomyopathy that experienced syncope, ventricular tachycardia, and sudden death (1985-1998). J Am Anim Hosp Assoc 2004, 40(1):24-28.
6. Calvert CA, Chapman WL Jr, Toal RL: Congestive cardiomyopathy in doberman pinscher dogs. J Am Vet Med Assoc 1982, 181(6):598-602.

7. Mausberg TB, Wess G, Simak J, Keller L, Drogemuller M, Drogemuller C, Webster MT, Stephenson H, Dukes-McEwan J, Leeb T: A locus on chromosome 5 is associated with dilated cardiomyopathy in doberman pinschers. PloS One 2011, 6(5):e20042.

8. Wess G, Schulze A, Butz V, Simak J, Killich M, Keller L, Maeurer J, Hartmann $\mathrm{K}$ : Prevalence of dilated cardiomyopathy in doberman pinschers in various age groups. J Vet Intern Med 2010, 24(3):533-538.

9. Calvert CA, Pickus CW, Jacobs GJ, Brown J: Signalment, survival, and prognostic factors in doberman pinschers with end-stage cardiomyopathy. J Vet Intern Med 1997, 11(6):323-326.

10. Calvert CA, Hall G, Jacobs G, Pickus C: Clinical and pathologic findings in doberman pinschers with occult cardiomyopathy that died suddenly or developed congestive heart failure: 54 cases (1984-1991). J Am Vet Med Assoc 1997, 210(4):505-511.

11. Petric AD, Stabej P, Zemva A: Dilated cardiomyopathy in doberman pinschers: survival, causes of death and a pedigree review in a related line. J Vet Cardiol 2002, 4(1):17-24.

12. Calvert CA, Jacobs G, Pickus CW, Smith DD: Results of ambulatory electrocardiography in overtly healthy doberman pinschers with echocardiographic abnormalities. J Am Vet Med Assoc 2000, 217(9):1328-1332.

13. Calvert CA, Jacobs GJ, Smith DD, Rathbun SL, Pickus CW: Association between results of ambulatory electrocardiography and development of cardiomyopathy during long-term follow-up of doberman pinschers. J Am Vet Med Assoc 2000, 216(1):34-39.

14. Hazlett MJ, Maxie MG, Allen DG, Wilcock BP: A retrospective study of heart disease in doberman pinscher dogs. Can Vet J 1983, 24(7):205-210.

15. O'Grady MR, O'Sullivan ML, Minors SL, Horne R: Efficacy of benazepril hydrochloride to delay the progression of occult dilated cardiomyopathy in doberman pinschers. J Vet Intern Med 2009, 23(5):977-983.

16. Oyama MA, Sisson DD, Solter PF: Prospective screening for occult cardiomyopathy in dogs by measurement of plasma atrial natriuretic peptide, B-type natriuretic peptide, and cardiac troponin-I concentrations. Am J Vet Res 2007, 68(1):42-47.

17. Oyama MA, Sisson DD: Cardiac troponin-I concentration in dogs with cardiac disease. J Vet Intern Med 2004, 18(6):831-839.

18. Spratt DP, Mellanby RJ, Drury N, Archer J: Cardiac troponin I: evaluation I of a biomarker for the diagnosis of heart disease in the dog. I Small Anim Pract 2005, 46(3):139-145.

19. O'Sullivan ML, O'Grady MR, Minors SL: Plasma big endothelin-1, atrial natriuretic peptide, aldosterone, and norepinephrine concentrations in normal doberman pinschers and doberman pinschers with dilated cardiomyopathy. J Vet Intern Med 2007, 21(1):92-99.

20. Wess G, Butz V, Mahling M, Hartmann K: Evaluation of N-terminal pro-Btype natriuretic peptide as a diagnostic marker of various stages of cardiomyopathy in doberman pinschers. Am J Vet Res 2011, 72(5):642-649.

21. Esquela-Kerscher A, Slack FJ: Oncomirs - microRNAs with a role in cancer. Nat Rev Cancer 2006, 6(4):259-269.

22. Zhang $S$, Chen $L$, Jung EJ, Calin GA: Targeting microRNAs with small molecules: from dream to reality. Clin Pharmacol Ther 2010, 87(6):754-758.

23. Friedman RC, Farh KK, Burge CB, Bartel DP: Most mammalian mRNAs are conserved targets of microRNAs. Genome Res 2009, 19(1):92-105.

24. Mitchell PS, Parkin RK, Kroh EM, Fritz BR, Wyman SK, Pogosova-Agadjanyan EL, Peterson A, Noteboom J, O'Briant KC, Allen A, et al: Circulating microRNAs as stable blood-based markers for cancer detection. Proc Natl Acad Sci USA 2008, 105(30):10513-10518.

25. Ai J, Zhang R, Li Y, Pu J, Lu Y, Jiao J, Li K, Yu B, Li Z, Wang R, et al: Circulating microRNA-1 as a potential novel biomarker for acute myocardial infarction. Biochem Biophys Res Commun 2010, 391(1):73-77.

26. Chen X, Ba Y, Ma L, Cai X, Yin Y, Wang K, Guo J, Zhang Y, Chen J, Guo X, et al: Characterization of microRNAs in serum: a novel class of biomarkers for diagnosis of cancer and other diseases. Cell Res 2008, 18(10):997-1006.

27. Etheridge A, Lee I, Hood L, Galas D, Wang K: Extracellular microRNA: a new source of biomarkers. Mutat Res 2011, 717(1-2):85-90.

28. Wang K, Zhang S, Marzolf B, Troisch P, Brightman A, Hu Z, Hood LE, Galas DJ: Circulating microRNAs, potential biomarkers for drug-induced liver injury. Proc Natl Acad Sci USA 2009, 106(11):4402-4407.

29. Tsujiura M, Ichikawa D, Komatsu S, Shiozaki A, Takeshita H, Kosuga T, Konishi $\mathrm{H}$, Morimura R, Deguchi K, Fujiwara $\mathrm{H}$, et al: Circulating microRNAs in 
plasma of patients with gastric cancers. Br J Cancer 2010, 102(7):1174-1179.

30. Heneghan HM, Miller N, Lowery AJ, Sweeney KJ, Newell J, Kerin MJ: Circulating microRNAs as novel minimally invasive biomarkers for breast cancer. Ann Surg 2010, 251(3):499-505.

31. Wang GK, Zhu JQ, Zhang JT, Li Q, Li Y, He J, Qin YW, Jing Q: Circulating microRNA: a novel potential biomarker for early diagnosis of acute myocardial infarction in humans. Eur Heart J 2010, 31(6):659-666.

32. Huang Z, Huang D, Ni S, Peng Z, Sheng W, Du X: Plasma microRNAs are promising novel biomarkers for early detection of colorectal cancer Int J Cancer 2010, 127(1):118-126.

33. Lodes MJ, Caraballo M, Suciu D, Munro S, Kumar A, Anderson B: Detection of cancer with serum miRNAs on an oligonucleotide microarray. PLoS One 2009, 4(7):e6229.

34. Zhang Y, Jia Y, Zheng R, Guo Y, Wang Y, Guo H, Fei M, Sun S: Plasma microRNA-122 as a biomarker for viral-, alcohol-, and chemical-related hepatic diseases. Clin Chem 2010, 56(12):1830-1838.

35. Baskerville S, Bartel DP: Microarray profiling of microRNAs reveals frequent coexpression with neighboring miRNAs and host genes. RNA 2005, 11(3):241-247.

36. Lagos-Quintana M, Rauhut R, Yalcin A, Meyer J, Lendeckel W, Tuschl T: Identification of tissue-specific microRNAs from mouse. Curr Biol 2002, 12(9):735-739.

37. Satoh M, Minami Y, Takahashi Y, Tabuchi T, Nakamura M: Expression of microRNA-208 is associated with adverse clinical outcomes in human dilated cardiomyopathy. J Card Fail 2010, 16(5):404-410.

38. Ikeda S, Pu WT: Expression and function of MicroRNAs in heart disease. Curr Drug Targets 2010, 11(8):913-925.

39. Cai B, Pan Z, Lu Y: The roles of microRNAs in heart diseases: a novel important regulator. Curr Med Chem 2010, 17(5):407-411.

40. van Rooij E, Olson EN: MicroRNAs: powerful new regulators of heart disease and provocative therapeutic targets. J Clin Invest 2007, 117(9):2369-2376.

41. Yang B, Lin H, Xiao J, Lu Y, Luo X, Li B, Zhang Y, Xu C, Bai Y, Wang H, et al: The muscle-specific microRNA miR-1 regulates cardiac arrhythmogenic potential by targeting GJA1 and KCNJ2. Nat Med 2007, 13(4):486-491.

42. Zhao Y, Ransom JF, Li A, Vedantham V, von Drehle M, Muth AN, Tsuchihashi T, McManus MT, Schwartz RJ, Srivastava D: Dysregulation of cardiogenesis, cardiac conduction, and cell cycle in mice lacking miRNA-1-2. Cell 2007, 129(2):303-317.

43. van Rooij E, Sutherland LB, Qi X, Richardson JA, Hill J, Olson EN: Control of stress-dependent cardiac growth and gene expression by a microRNA. Science 2007, 316(5824):575-579.

44. van Rooij E, Sutherland LB, Liu N, Williams AH, McAnally J, Gerard RD, Richardson JA, Olson EN: A signature pattern of stress-responsive microRNAs that can evoke cardiac hypertrophy and heart failure. Proc Natl Acad Sci USA 2006, 103(48):18255-18260.

45. Chen JF, Murchison EP, Tang R, Callis TE, Tatsuguchi M, Deng Z, Rojas M, Hammond SM, Schneider MD, Selzman CH, et al: Targeted deletion of Dicer in the heart leads to dilated cardiomyopathy and heart failure. Proc Natl Acad Sci USA 2008, 105(6):2111-2116.

46. Rao PK, Toyama Y, Chiang HR, Gupta S, Bauer M, Medvid R, Reinhardt F, Liao R, Krieger $M$, Jaenisch $R$, et al: Loss of cardiac microRNA-mediated regulation leads to dilated cardiomyopathy and heart failure. Circ Res 2009, 105(6):585-594

47. Liu N, Bezprozvannaya S, Williams AH, Qi X, Richardson JA, Bassel-Duby R, Olson EN: microRNA-133a regulates cardiomyocyte proliferation and suppresses smooth muscle gene expression in the heart. Genes Dev 2008, 22(23):3242-3254

48. Ikeda S, Kong SW, Lu J, Bisping E, Zhang H, Allen PD, Golub TR, Pieske B, Pu WT: Altered microRNA expression in human heart disease. Physiol Genomics 2007, 31(3):367-373.

49. Sucharov $C$, Bristow MR, Port JD: miRNA expression in the failing human heart: functional correlates. J Mol Cell Cardiol 2008, 45(2):185-192.

50. Satoh M, Minami Y, Takahashi Y, Tabuchi T, Nakamura M: A cellular MicroRNA, let-7i, is a novel biomarker for clinical outcome in patients with dilated cardiomyopathy. J Card Fail 2011, 17(11):923-929.

51. Zhou B, Rao L, Peng Y, Wang Y, Chen Y, Song Y, Zhang L: Common genetic polymorphisms in pre-microRNAs were associated with increased risk of dilated cardiomyopathy. Clin Chim Acta 2010, 32(1):60-65.
52. Voellenkle C, van Rooij J, Cappuzzello C, Greco S, Arcelli D, Di Vito L, Melillo $G$, Rigolini R, Costa E, Crea F, et al: MicroRNA signatures in peripheral blood mononuclear cells of chronic heart failure patients. Physiol Genomics 2010, 42(3):420-426.

53. Tijsen AJ, Creemers EE, Moerland PD, de Windt LJ, van der Wal AC, Kok WE, Pinto YM: MiR423-5p as a circulating biomarker for heart failure. Circ Res 2010, 106(6):1035-1039.

54. Zampetaki A, Willeit P, Tilling L, Drozdov I, Prokopi M, Renard JM, Mayr A Weger S, Schett G, Shah A, et al: Prospective study on circulating MicroRNAs and risk of myocardial infarction. J Am Coll Cardiol 2012, 60(4):290-299.

55. Van Empel VP, De Windt LJ, Martins PA: Circulating miRNAs: reflecting or affecting cardiovascular disease. Curr Hypertens Rep 2012, 14(6):498-509.

56. Elton TS, Khan M, Terentyev D: MicroRNAs in cardiovascular disease. F1000 Med Rep 2011, 3:10.

57. Ji X, Takahashi R, Hiura Y, Hirokawa G, Fukushima Y, Iwai N: Plasma miR-208 as a biomarker of myocardial injury. Clin Chem 2009, 55(11):1944-1949.

58. Dorn GW 2nd: MicroRNAs in cardiac disease. Trans/ Res 2011, 157(4):226-235.

59. Mizuno H, Nakamura A, Aoki Y, Ito N, Kishi S, Yamamoto K, Sekiguchi M, Takeda S, Hashido K: Identification of muscle-specific MicroRNAs in serum of muscular dystrophy animal models: promising novel blood-based markers for muscular dystrophy. PLoS One 2011, 6(3):e18388.

60. Zhou D, Li S, Wen J, Gong X, Xu L, Luo Y: Genome-wide computational analyses of microRNAs and their targets from Canis familiaris. Comput Biol Chem 2008, 32(1):60-65.

61. Boggs RM, Moody JA, Long CR, Tsai KL, Murphy KE: Identification, amplification and characterization of miR-17-92 from canine tissue. Gene 2007, 404(1-2):25-30.

62. Gioia G, Mortarino M, Gelain ME, Albonico F, Ciusani E, Forno I, Marconato L, Martini $V$, Comazzi S: Immunophenotype-related microRNA expression in canine chronic lymphocytic leukemia. Vet Immunol Immunopathol 2011, 142(3-4):228-235.

63. Boggs RM, Wright ZM, Stickney MJ, Porter WW, Murphy KE: MicroRNA expression in canine mammary cancer. Mamm Genome 2008, 19(7-8):561-569.

64. Mortarino M, Gioia G, Gelain ME, Albonico F, Roccabianca P, Ferri E, Comazzi S: Identification of suitable endogenous controls and differentially expressed microRNAs in canine fresh-frozen and FFPE lymphoma samples. Leuk Res 2010, 34(8):1070-1077.

65. Thum T, Galuppo P, Wolf C, Fiedler J, Kneitz S, van Laake LW, Doevendans PA, Mummery CL, Borlak J, Haverich A, et al: MicroRNAs in the human heart: a clue to fetal gene reprogramming in heart failure. Circulation 2007, 116(3):258-267

66. Thum T, Gross C, Fiedler J, Fischer T, Kissler S, Bussen M, Galuppo P, Just S, Rottbauer W, Frantz S, et al: MicroRNA-21 contributes to myocardial disease by stimulating MAP kinase signalling in fibroblasts. Nature 2008 456(7224):980-984.

67. Cheng $Y$, Tan N, Yang J, Liu X, Cao X, He P, Dong X, Qin S, Zhang C: A translational study of circulating cell-free microRNA-1 in acute myocardial infarction. Clin Sci (Lond) 2010, 119(2):87-95.

68. Kroh EM, Parkin RK, Mitchell PS, Tewari M: Analysis of circulating microRNA biomarkers in plasma and serum using quantitative reverse transcription-PCR (qRT-PCR). Methods 2010, 50(4):298-301.

69. Cannarozzi G, Schneider A, Gonnet G: A phylogenomic study of human, dog, and mouse. PLoS Comput Biol 2007, 3(1):e2.

70. Lunter G: Dog as an outgroup to human and mouse. PLoS Comput Biol 2007, 3(4):e74.

71. Zhao $Y$, Sheng Z, Huang J: A systematic analysis of heart transcriptome highlights divergent cardiovascular disease pathways between animal models and humans. Mol Biosyst 2012, 8(2):504-510.

72. Chen XM, Splinter PL, O'Hara SP, LaRusso NF: A cellular micro-RNA, let-7i, regulates Toll-like receptor 4 expression and contributes to cholangiocyte immune responses against Cryptosporidium parvum infection. J Biol Chem 2007, 282(39):28929-28938.

73. Satoh M, Nakamura M, Akatsu T, Shimoda Y, Segawa I, Hiramori K: Toll-like receptor 4 is expressed with enteroviral replication in myocardium from patients with dilated cardiomyopathy. Lab Invest 2004, 84(2):173-181.

74. Frankel LB, Wen J, Lees M, Hoyer-Hansen M, Farkas T, Krogh A, Jaattela M, Lund AH: microRNA-101 is a potent inhibitor of autophagy. EMBO J 2011, 30(22):4628-4641. 
75. Su H, Yang JR, Xu T, Huang J, Xu L, Yuan Y, Zhuang SM: MicroRNA-101, down-regulated in hepatocellular carcinoma, promotes apoptosis and suppresses tumorigenicity. Cancer Res 2009, 69(3):1135-1142.

76. Krichevsky AM, Gabriely G: miR-21: a small multi-faceted RNA. J Cell Mol Med 2009, 13(1):39-53.

77. Selcuklu SD, Donoghue MT, Spillane C: miR-21 as a key regulator of oncogenic processes. Biochem Soc Trans 2009, 37(Pt 4):918-925.

78. Ji R, Cheng Y, Yue J, Yang J, Liu X, Chen H, Dean DB, Zhang C: MicroRNA expression signature and antisense-mediated depletion reveal an essential role of MicroRNA in vascular neointimal lesion formation. Circ Res 2007, 100(11):1579-1588.

79. Suarez Y, Fernandez-Hernando C, Pober JS, Sessa WC: Dicer dependent microRNAs regulate gene expression and functions in human endothelial cells. Circ Res 2007, 100(8):1164-1173.

80. Cheng Y, Ji R, Yue J, Yang J, Liu X, Chen H, Dean DB, Zhang C: MicroRNAs are aberrantly expressed in hypertrophic heart: do they play a role in cardiac hypertrophy? Am J Pathol 2007, 170(6):1831-1840.

81. Roy S, Khanna S, Hussain SR, Biswas S, Azad A, Rink C, Gnyawali S, Shilo S, Nuovo GJ, Sen CK: MicroRNA expression in response to murine myocardial infarction: miR-21 regulates fibroblast metalloprotease- 2 via phosphatase and tensin homologue. Cardiovasc Res 2009, 82(1):21-29.

82. Tatsuguchi M, Seok HY, Callis TE, Thomson JM, Chen JF, Newman M, Rojas M, Hammond SM, Wang DZ: Expression of microRNAs is dynamically regulated during cardiomyocyte hypertrophy. J Mol Cell Cardiol 2007, 42(6):1137-1141.

83. Sayed D, Hong C, Chen IY, Lypowy J, Abdellatif M: MicroRNAs play an essential role in the development of cardiac hypertrophy. Circ Res 2007, 100(3):416-424.

84. Dong S, Cheng Y, Yang J, Li J, Liu X, Wang X, Wang D, Krall TJ, Delphin ES, Zhang C: MicroRNA expression signature and the role of microRNA-21 in the early phase of acute myocardial infarction. J Biol Chem 2009, 284(43):29514-29525.

85. van Rooij E, Sutherland LB, Thatcher JE, DiMaio JM, Naseem RH, Marshall WS, Hill JA, Olson EN: Dysregulation of microRNAs after myocardial infarction reveals a role of miR-29 in cardiac fibrosis. Proc Natl Acad Sci USA 2008, 105(35):13027-13032.

86. Everett RM, McGann J, Wimberly HC, Althoff J: Dilated cardiomyopathy of Doberman pinschers: retrospective histomorphologic evaluation of heart from 32 cases. Vet Pathol 1999, 36(3):221-227.

87. Tidholm A, Jonsson L: Histologic characterization of canine dilated cardiomyopathy. Vet Pathol 2005, 42(1):1-8.

88. Orenes-Pinero E, Montoro-Garcia S, Patel JV, Valdes M, Marin F, Lip GY: Role of microRNAs in cardiac remodelling: New insights and future perspectives. Int J Cardiol 2012, pii: S0167-5273(12)01241-7. doi:10.1016/j. ijcard.2012.09.120. [Epub ahead of print]

89. Liu F, Yin L, Zhang L, Liu W, Liu J, Wang Y, Yu B: Trimetazidine improves right ventricular function by increasing miR-21 expression. Int J Mol Med 2012, 30(4):849-855.

90. Bonauer A, Carmona G, Iwasaki M, Mione M, Koyanagi M, Fischer A, Burchfield J, Fox H, Doebele C, Ohtani K, et al: MicroRNA-92a controls angiogenesis and functional recovery of ischemic tissues in mice. Science 2009, 324(5935):1710-1713.

91. Zhang $X$, Wang $X$, Zhu H, Zhu C, Wang Y, Pu WT, Jegga AG, Fan GC: Synergistic effects of the GATA-4-mediated miR-144/451 cluster in protection against simulated ischemia/reperfusion-induced cardiomyocyte death. J Mol Cell Cardiol 2010, 49(5):841-850.

92. Jeong MH, Lee JS, Kim DH, Park WJ, Yang DK: Identification of novel microRNAs negatively regulating cardiac hypertrophy. Biochem Biophys Res Commun 2012

93. Wang K, Zhang S, Weber J, Baxter D, Galas DJ: Export of microRNAs and microRNA-protective protein by mammalian cells. Nucleic Acids Res 2010, 38(20):7248-7259.

94. Creemers EE, Tijsen AJ, Pinto YM: Circulating microRNAs: novel biomarkers and extracellular communicators in cardiovascular disease? Circ Res 2012, 110(3):483-495.

95. Vickers KC, Palmisano BT, Shoucri BM, Shamburek RD, Remaley AT: MicroRNAs are transported in plasma and delivered to recipient cells by high-density lipoproteins. Nat Cell Bio/ 2011, 13(4):423-433.

96. Arroyo JD, Chevillet JR, Kroh EM, Ruf IK, Pritchard CC, Gibson DF, Mitchell PS, Bennett CF, Pogosova-Agadjanyan EL, Stirewalt DL, et al: Argonaute2 complexes carry a population of circulating microRNAs independent of vesicles in human plasma. Proc Natl Acad Sci USA 2011, 108(12):5003-5008.

97. Valadi H, Ekstrom K, Bossios A, Sjostrand M, Lee JJ, Lotvall JO: Exosomemediated transfer of mRNAs and microRNAs is a novel mechanism of genetic exchange between cells. Nat Cell Biol 2007, 9(6):654-659.

98. Ohshima K, Inoue K, Fujiwara A, Hatakeyama K, Kanto K, Watanabe Y, Muramatsu K, Fukuda Y, Ogura S, Yamaguchi K, et al: Let-7 microRNA family is selectively secreted into the extracellular environment via exosomes in a metastatic gastric cancer cell line. PLoS One 2010, 5(10):e13247.

99. Lee YS, Pressman S, Andress AP, Kim K, White JL, Cassidy JJ, Li X, Lubell K, Lim Do H, Cho IS, et al: Silencing by small RNAs is linked to endosomal trafficking. Nat Cell Biol 2009, 11(9):1150-1156.

100. Zhang Y, Liu D, Chen X, Li J, Li L, Bian Z, Sun F, Lu J, Yin Y, Cai X, et al: Secreted monocytic miR-150 enhances targeted endothelial cell migration. Mol Cell 2010, 39(1):133-144.

101. Summerfield NJ, Boswood A, O'Grady MR, Gordon SG, Dukes-McEwan J, Oyama MA, Smith S, Patteson M, French AT, Culshaw GJ, et al: Efficacy of pimobendan in the prevention of congestive heart failure or sudden death in doberman pinschers with preclinical dilated cardiomyopathy (the PROTECT study). J Vet Intern Med 2012, 26(6):1337-1349.

102. Wess G, Maurer J, Simak J, Hartmann K: Use of Simpson's method of disc to detect early echocardiographic changes in doberman pinschers with dilated cardiomyopathy. J Vet Intern Med 2010, 24(5):1069-1076.

103. Griffiths-Jones S: The microRNA registry. Nucleic Acids Res 2004, 32(Database issue):D109-D111.

104. Huber W, von Heydebreck A, Sultmann H, Poustka A, Vingron M: Variance stabilization applied to microarray data calibration and to the quantification of differential expression. Bioinformatics 2002, 18(Suppl 1):S96-S104.

105. Smyth GK, Speed T: Normalization of cDNA microarray data. Methods 2003, 31(4):265-273.

106. Pfaffl MW: A new mathematical model for relative quantification in realtime RT-PCR. Nucleic Acids Res 2001, 29(9):e45.

107. Pfaffl MW, Horgan GW, Dempfle L: Relative expression software tool (REST) for group-wise comparison and statistical analysis of relative expression results in real-time PCR. Nucleic Acids Res 2002, 30(9):e36.

doi:10.1186/1746-6148-9-12

Cite this article as: Steudemann et al.: Detection and comparison of microRNA expression in the serum of Doberman Pinschers with dilated cardiomyopathy and healthy controls. BMC Veterinary Research 2013 9:12.

\section{Submit your next manuscript to BioMed Central and take full advantage of:}

- Convenient online submission

- Thorough peer review

- No space constraints or color figure charges

- Immediate publication on acceptance

- Inclusion in PubMed, CAS, Scopus and Google Scholar

- Research which is freely available for redistribution 